This item was submitted to Loughborough's Research Repository by the author.

Items in Figshare are protected by copyright, with all rights reserved, unless otherwise indicated.

\title{
The effects of local versus systemic passive heating on the acute inflammatory, vascular and glycaemic response
}

\section{PLEASE CITE THE PUBLISHED VERSION}

https://doi.org/10.1139/apnm-2020-0704

\section{PUBLISHER}

NRC Research Press

VERSION

AM (Accepted Manuscript)

\section{PUBLISHER STATEMENT}

This paper was accepted for publication in the journal Applied Physiology, Nutrition, and Metabolism and the definitive published version is available at https://doi.org/10.1139/apnm-2020-0704.

LICENCE

CC BY-NC-ND 4.0

\section{REPOSITORY RECORD}

Hoekstra, Sven, Takahiro Ogawa, Miguel Dos Santos, Greg Handsley, Stephen Bailey, Vicky Goosey-Tolfrey, Fumihiro Tajima, Jem Cheng, and Christof Leicht. 2021. "The Effects of Local Versus Systemic Passive Heating on the Acute Inflammatory, Vascular and Glycaemic Response". Loughborough University. https://hdl.handle.net/2134/13526198.v1. 


\section{Applied Physiology, Nutrition, and Metal}

\section{The effects of local versus systemic passive heating on the acute inflammatory, vascular and glycaemic response}

\begin{tabular}{|r|l|}
\hline Journal: & Applied Physiology, Nutrition, and Metabolism \\
\hline Manuscript ID & apnm-2020-0704.R2 \\
\hline Danuscript Type: & Article \\
\hline Author: & n/a \\
\hline Complete List of Authors: & $\begin{array}{l}\text { Hoekstra, Sven; Loughborough University, School of Sport, Exercise and } \\
\text { Health Sciences } \\
\text { Ogawa, Takahiro; Wakayama Medical University } \\
\text { Dos Santos, Miguel; Loughborough University } \\
\text { Handsley, Greg; Loughborough University } \\
\text { Bailey, Stephen; Loughborough University, School of Sport, Exercise and } \\
\text { Health Sciences; } \\
\text { Goosey-Tolfrey, Victoria; Loughborough University, } \\
\text { Tajima, Fumihiro; Wakayama Medical University } \\
\text { Cheng, Jem; McMaster University } \\
\text { Leicht, Christof; Loughborough University, SSEHS }\end{array}$ \\
\hline $\begin{array}{r}\text { Novelty bullets: points that } \\
\text { summarize the key findings in } \\
\text { the work: }\end{array}$ & $\begin{array}{l}\text { Upper-body cooling attenuates the plasma nitrite, interleukin-1ra and } \\
\text { femoral artery shear rate response to passive heating., Upper-body } \\
\text { cooling leads to more positive perceptual responses to passive heating., } \\
\text { The increase in the interleukin-6 incremental area under the curve after } \\
\text { passive heating is not reduced by upper-body cooling }\end{array}$ \\
\hline Keyword: & $\begin{array}{l}\text { Chronic low-grade inflammation, Glucose metabolism, Heat therapy, } \\
\text { Interleukin-6, Thermal comfort, Blood flow }\end{array}$ \\
\hline $\begin{array}{r}\text { Is the invited manuscript for } \\
\text { consideration in a Special } \\
\text { Issue? : }\end{array}$ & \begin{tabular}{l} 
Not applicable (regular submission) \\
\hline
\end{tabular} \\
\hline
\end{tabular}

\section{SCHOLARONE \\ Manuscripts}




\section{The effects of local versus systemic passive heating on the acute inflammatory, vascular and glycaemic response}

Sven P. Hoekstra ${ }^{1,2,3}$, Takahiro Ogawa ${ }^{3}$, Miguel Dos Santos ${ }^{2}$, Greg Handsley², Stephen J.

Bailey $^{2}$, Victoria L. Goosey-Tolfrey ${ }^{1,2}$, Fumihiro Tajima ${ }^{1,3}$, Jem L. Cheng ${ }^{4}$, Christof A. Leicht ${ }^{1,2}$

1. The Peter Harrison Centre for Disability Sport; Loughborough University; Loughborough; United Kingdom

2. School of Sport, Exercise and Health Sciences; Loughborough University; Loughborough; United Kingdom

3. Department of Rehabilitation Medicine; Wakayama Medical University; Wakayama; Japan

4. Department of Kinesiology; McMaster University; Hamilton; Ontario; Canada

\section{Email addresses:}

Sven Hoekstra: s.p.hoekstra@,1boro.ac.uk

Takahiro Ogawa: ogawa0417takahiro@yahoo.ne.jp

Miguel Dos Santos: miguel.migueldossantos@gmail.com

Greg Handsley: greghandsley@googlemail.com

Stephen Bailey: s.bailey2@1boro.ac.uk

Victoria Goosey-Tolfrey: v.1.tolfrey@lboro.ac.uk

Fumihiro Tajima: tajibun@gmail.com

Jem Cheng: chengj12@mcmaster.ca

Christof Leicht: c.a.leicht@1boro.ac.uk

\section{Corresponding author}

Dr Christof Leicht (http://orcid.org/0000-0002-3539-8480)

The Peter Harrison Centre for Disability Sport; Loughborough University

LE11 3TU Loughborough; United Kingdom

c.a.leicht@lboro.ac.uk 
Abstract

37

The aim of this study was to compare the acute cardiometabolic and perceptual responses between local and whole-body passive heating. Using a water-perfused suit, ten recreationally active males underwent three 90 min conditions: heating of the legs with upper-body cooling (LBH), whole-body heating (WBH) and exposure to a thermoneutral temperature (CON). Blood samples were collected before and up to $3 \mathrm{~h}$ post-session to assess inflammatory markers, while a $2 \mathrm{~h}$ oral glucose tolerance test was initiated $1 \mathrm{~h}$ post-session. Femoral artery shear rate and perceptual responses were recorded at regular intervals. The interleukin (IL)- 6 incremental area under the curve (iAUC) was higher for LBH (1096 $\pm 851 \mathrm{pg} / \mathrm{mL} * 270 \mathrm{~min})$ and $\mathrm{WBH}(833 \pm 476$ $\mathrm{pg} / \mathrm{mL} * 270 \mathrm{~min})$ compared with $\operatorname{CON}(565 \pm 325 \mathrm{pg} / \mathrm{mL} * 270 \mathrm{~min} ; p<0.047)$. Glucose concentrations were higher after WBH compared with LBH and CON $(p<0.046)$. Femoral artery shear rate was higher at the end of WBH $(1713 \pm 409 \mathrm{~L} / \mathrm{min})$ compared with LBH $(943 \pm 349 \mathrm{~L} / \mathrm{min} ; p<0.001)$, and higher in LBH than CON $(661 \pm 222 \mathrm{~L} / \mathrm{min}$; $p=0.002$ ). Affect and thermal comfort were more negative during WBH compared with LBH and CON $(p<0.010)$. In conclusion, local passive heating elevated shear rate and the IL-6 iAUC. However, while resulting in more positive perceptual responses, the majority of the included cardiometabolic markers were attenuated compared with WBH.

- The increase in the interleukin-6 incremental area under the curve in response to passive heating is not reduced by upper-body cooling.

- Upper-body cooling attenuates the plasma nitrite, interleukin-1ra and femoral artery shear rate response to passive heating.

- Upper-body cooling leads to more positive perceptual responses to passive heating. 
60 Chronic low-grade inflammation; Glucose metabolism; Heat therapy; Interleukin-6;

61 Thermal comfort; Blood flow

62

63

64

65

66

67

68

69

70

71

72

73

74

75

76

77

78

(c) The Author(s) or their Institution(s) 


\section{Introduction}

Passively elevating body temperature, by means of sauna bathing or hot water immersion (HWI) for example, is increasingly recognised as a strategy to promote cardiometabolic health (Hoekstra et al., 2020). The acute effects of whole-body passive heating methods are well-characterised, with recent research interest focusing on metabolic, inflammatory and vascular markers (Maley et al., 2019; Cullen et al., 2020). For instance, a single HWI session acutely elevates the concentration of inflammatory markers interleukin (IL)-6 and IL-1ra, postprandial glucose concentration and femoral artery blood flow (Laing et al., 2008; Chiesa et al., 2015; Maley et al., 2019). Although previous studies that have investigated the effects of HWI suggest the existence of a dose-response relationship between the rise in core temperature $\left(\mathrm{T}_{\text {core }}\right)$ and changes in inflammatory and cardiometabolic markers (Laing et al., 2008; Leicht et al., 2017; Leicht et al., 2015; Hoekstra et al., 2018), it is not known whether an increase in $\mathrm{T}_{\text {core }}$ is essential to induce such responses. Investigating passive heating protocols with a limited rise in $\mathrm{T}_{\text {core }}$ can provide mechanistic insight into the physiological factors that $\underline{\text { stimulate cardiometabolic responses following heat stress, while they can also inform }}$ the creation of accessible and tolerable passive heating protocols. For instance, localised heating (when compared with whole-body heating) may result in more favourable perceptual responses (Mündel et al., 2006), which could enhance the accessibility of this intervention.

There are several reasons to suggest that local passive heating with a limited $\mathrm{T}_{\text {core }}$ rise can stimulate changes in cardiometabolic markers. Ex vivo studies using rodent tissue indicate that at least part of the acute effects of heating may be evoked by the elevation of skeletal muscle temperature per se. For instance, heating of skeletal muscle 
induces the production and release of IL-6 (Welc et al., 2012). In the context of exercise, IL-6 is considered key to induce its anti-inflammatory effects by stimulating the production of anti-inflammatory cytokines such as IL-1ra (Petersen \& Pedersen, 2005; Steensberg et al., 2003). Whole-body heating protocols leading to a $\mathrm{T}_{\text {core }}$ increase between $\sim 1.5^{\circ} \mathrm{C}$ and $\sim 2^{\circ} \mathrm{C}$ have consistently shown that passive heating can also increase IL-6 concentration (Laing et al., 2008; Leicht et al., 2015; Hoekstra et al., 2018). Interestingly, lower-body heating resulting in a more modest $\mathrm{T}_{\text {core }}$ rise (i.e. $1^{\circ} \mathrm{C}$ ) also acutely elevates IL-6 concentration (Hashizaki et al., 2018), providing preliminary support for the notion that providing the large muscle mass in the legs is heated, a large elevation in $\mathrm{T}_{\text {core }}$ may not be needed to induce an acute IL-6 response.

Passive heating also has a potent effect on the cardiovascular system, stimulating an increase in cardiac output, arterial blood flow and shear stress (Chiesa et al., 2015). Acute increases in shear stress through heating or exercise stimulate positive adaptations in endothelial function (Laughlin et al., 2008), an important cardiovascular disease risk factor (Ras et al., 2013). Furthermore, an increase in arterial blood flow facilitates glucose delivery to skeletal muscle (Baron et al., 1994), whilst the associated increase in nitric oxide bioavailability may further stimulate glucose uptake (Roberts et al., 1997). In keeping with the acute inflammatory response to heating, there is evidence to suggest that a large rise in $\mathrm{T}_{\text {core }}$ may not be needed to stimulate femoral artery blood flow and shear stress through passive heat stress. For instance, heating of one leg without a concomitant rise in $\mathrm{T}_{\text {core }}$ increases common femoral artery blood flow to a similar extent compared with systemic heating (Chiesa et al., 2015).

Although ex vivo heating of skeletal muscle tissue increases glucose uptake (Koshinaka et al., 2013) and passive heating acutely increases insulin sensitivity in 
animals (Gupte et al., 2011), human in vivo studies have reported elevated blood glucose concentrations in response to an oral glucose tolerance test (OGTT) during (Dumke et al., 2015) or following whole-body heating (Leicht et al., 2019). It has been suggested that the acute elevation in glucose concentrations results from an increase in hepatic glucose output mediated by an enhanced production of catecholamines (Leicht et al., 2019; Hargreaves et al., 1996). As $\mathrm{T}_{\text {core }}$ strongly correlates with catecholamine production (Frank et al., 1999), reducing the rise in $\mathrm{T}_{\text {core }}$ during passive heating is likely to attenuate the increase in plasma catecholamine as well as glucose concentrations. Lowering the glycaemic response may make passive heating more suitable for persons with impaired glucose metabolism (e.g. persons with non-diabetic hyperglycaemia or Type 2 diabetes mellitus) (Kitabchi et al., 2001).

This study investigated the acute inflammatory, vascular, glycaemic and perceptual responses to whole-body heating as well as local heating combined with upper-body cooling to limit the rise in $\mathrm{T}_{\text {core. }}$ It was hypothesised that: 1) passive heating of the lower limbs in combination with upper-body cooling (LBH) and WBH would both acutely increase systemic IL-6, IL-1ra and nitrite concentrations as well as femoral artery blood flow compared to a normothermic control condition (CON); 2) blood glucose concentrations during an OGTT conducted following LBH would be lower compared with $\mathrm{WBH}_{2} 3$ ) LBH would result in more positive perceptual responses compared with WBH.

\section{Methods}

Ten recreationally active, young adult males (age: $24 \pm 3 \mathrm{yrs}$; height: $184 \pm 6 \mathrm{~cm}$; body mass: $80.4 \pm 15.2 \mathrm{~kg}$; BMI: $23.0 \pm 4.9 \mathrm{~kg} / \mathrm{m}^{2}$; body fat percentage: $15.7 \pm 4.2 \%$ ) 
participated in this study after providing written informed consent. The sample size calculation was based on Hashizaki et al. (2018), who found an acute increase in IL-6 concentration after lower-body heating with a Cohen`s $d$ effect size of 1.1. Assuming a power of 0.8 and an $\alpha$ of 0.05 , ten participants would be required to detect a change in IL-6 concentration. Exclusion criteria were smoking, the use of anti-inflammatory medication and engaging in structured exercise for less than two or more than eight $\mathrm{h} /$ week. The study was approved by the local ethics committee of Loughborough University (project code: R19-P084), according to the declaration of Helsinki, but was not registered in a trial database.

\section{Study design}

Participants visited the laboratory following an overnight fast on three occasions, separated by at least $72 \mathrm{~h}$. On the day prior to each visit, diet was standardised using a food diary, while participants avoided exercise and the consumption of caffeine and alcohol. In a randomised order, determined using online randomising software, participants undertook three 90-min experimental conditions: whole-body heating (WBH), lower-body heating with simultaneous cooling of the upper body (LBH) and exposure to a thermoneutral temperature (CON) (Fig. 1). Manipulation of body temperature was performed using a water-perfused suit (Med-Eng, Ottawa, Canada), with separate controls for the lower and upper body segments. Participants wore tight-fitting Lycra sportswear over the suit to ensure direct contact of the suit with the skin, while emergency blankets were applied to prevent heat loss during WBH and LBH. During LBH, six frozen cool packs $(15 \mathrm{~cm} \times 8 \mathrm{~cm})$ were applied to the upper body, and replaced with colder counterparts after $45 \mathrm{~min}$. The packs were placed under the Lycra shirt, to be kept close to the body, and were positioned under the arms, and on 
the chest and abdomen. Ambient temperature and relative humidity in the laboratory were $24.4 \pm 0.6^{\circ} \mathrm{C}$ and $44 \pm 8 \%$ during $\mathrm{CON}, 24.6 \pm 0.7^{\circ} \mathrm{C}$ and $43 \pm 9 \%$ during $\mathrm{LBH}$, and $24.5 \pm 1.0^{\circ} \mathrm{C}$ and $46 \pm 8 \%$ during $\mathrm{WBH}$.

\section{Procedures}

The procedures during each visit are shown in Fig.1. On the first visit for each participant, anthropometric measures of height, weight and skinfold thickness (biceps, triceps, supra-iliac and subscapular) for the estimation of body fat percentage (Durnin and Womersley, 1974) were performed. Thereafter, participants applied a rectal temperature probe $10 \mathrm{~cm}$ beyond the anal sphincter for the measurement of rectal temperature $\left(\mathrm{T}_{\text {rec }}\right)$, while a zero-heat flux temperature sensor (Bair Hugger, 3M, Minnesota, USA) was placed on the skin at the muscle belly of the vastus lateralis to measure deep tissue temperature $\left(\mathrm{T}_{\mathrm{dt}}\right)$. The sensor was covered by a small Tupperware box to limit any thermal effects of the water-perfused suit. Nude body mass was then assessed to the nearest $0.1 \mathrm{~kg}$ (Seca 284, Hamburg, Germany). Skin thermometers were fitted on the chest, triceps, thigh and calf (Squirrel, Grant Instruments, Shepreth, UK), and a cannula was inserted into an antecubital vein. Thereafter, participants rested in a supine position for 60 min wearing shorts and a T-shirt. At the end of the rest period, the temperature measures as well as heart rate (HR; Polar, Kempele, Finland) and blood pressure (Microlife, Cambridge, UK) were recorded. Additionally, participants reported their thermal sensation (TS; Epstein and Moran, 2006) and thermal comfort (TC;

Epstein and Moran, 2006), while basic affect was measured by the Feeling Scale (FS; Hardy and Rejeski, 1989). Thereafter, participants put on the water-perfused suit and the experimental condition was started. Physiological and perceptual measures were assessed every 15 min during the 90 -min sessions, as well as 30, 60 and 90 min post- 
session. Participants were provided with water during the sessions to offset weight loss through sweating. During WBH, $150 \mathrm{~mL}$ of water was provided prior to and at $15 \mathrm{~min}$ intervals during heating. One hundred $\mathrm{mL}$ water was provided before and at the end of heating during $\mathrm{LBH}$, while $50 \mathrm{~mL}$ was provided during CON directly following the 90 min session.

At the end of the session, the water-perfused suit was removed, a blood sample was collected, and the participant remained supine for an additional $30 \mathrm{~min}$. Thereafter, nude body mass was reassessed. Following a further 30 min of supine rest, a 2 h OGTT was started with a blood sample and the ingestion of $82.5 \mathrm{~g}$ of dextrose dissolved in 300 $\mathrm{ml}$ of water. Participants remained seated during these $2 \mathrm{~h}$, except from 20 to $40 \mathrm{~min}$ after consuming the dextrose solution, when they were asked to change to a supine position. This was to accommodate for the ultrasound measures, which were performed 30 min post-drink.

\section{Ultrasonography}

Brachial artery blood flow and cardiac output were assessed following $30 \mathrm{~min}$ of supine rest (baseline), immediately following the session, as well as $90 \mathrm{~min}$ postsession. In addition, blood flow in the common femoral artery was assessed after $30 \mathrm{~min}$ of supine rest (baseline), 45 min into the session, during the final 2 min of the session, and 90 min post-session. When assessed at the same time points, common femoral artery blood flow measures preceded brachial artery blood flow and cardiac output measurements, respectively. This order was chosen as measurements of blood flow to the large muscle mass in the legs was the primary cardiovascular outcome measure. A water-proof marker and tape were used to ensure measurements were made at the same position throughout the trials. To access the common femoral artery during the sessions, 
a small opening was created in between two emergency blankets and both parts of the water-perfused suit.

Arterial blood flow and shear rate were assessed by ultrasonography (GE

Healthcare, Chicago IL, USA) in duplicate at each time point and in the Doppler mode, which records arterial images and blood velocity signals simultaneously. Non-blinded measurements and analyses were performed by the same experienced ultrasonographer (T.O., 20 years of experience in ultrasonography), with a $\mathrm{CV}$ of $3.7 \%$ for femoral artery blood flow and 5.4\% for brachial artery blood flow based on the baseline data obtained in CON. A16 MHz linear array transducer was used, and images were acquired at an insonation angle of $60^{\circ}$ for 10 heart cycles. Arterial diameter was measured by identifying the adventitial border of the near and far walls of the artery using the built-in caliper function on the ultrasound unit. Two caliper measurements per image were taken and averaged to yield a diameter value. Blood flow was calculated as the product of the mean blood velocity during a cardiac cycle and the cross-sectional area of the vessel. Shear rate was calculated by the following formula: $4 *$ mean blood velocity/vessel diameter) (Thomas et al., 2017). Vascular conductance in the femoral artery was determined as femoral artery blood flow/mean arterial pressure; the latter calculated as (systolic blood pressure + (diastolic blood pressure*2))/3 (Dinenno et al., 1999).

Stroke volume and cardiac output were also measured by Doppler ultrasound (GE Healthcare, Chicago IL, USA), via the Doppler method (Lewis et al., 1984). Using a M5S transducer and keeping the participant in the left lateral decubitus position, left ventricular outflow tract diameter was measured using a parasternal long-axis view, while left ventricular flow (velocity time integral) was acquired in the 3- or 5- chamber view obtained immediately proximal to the aortic valve. These two variables were then 
246 used to calculate stroke volume. All cardiac measurements and analyses were performed

247 by the same unblinded ultrasonographer (T.O.). Cardiac output was obtained as the 248 product of stroke volume and HR.

Blood analyses

After removing the first $2 \mathrm{ml}$, blood was directly drawn into a $\mathrm{K}_{3}$ EDTA and lithium-heparin monovettes and centrifuged for $10 \mathrm{~min}$ at $2360 \mathrm{~g}$ and $4^{\circ} \mathrm{C}$. Plasma aliquots were stored at $-80^{\circ} \mathrm{C}$ until batch analysis. Enzyme-linked immunosorbent assays were used to determine IL-6 (High sensitivity, R\&D systems, Abingdon, United Kingdom), IL-1ra (R\&D systems, Abingdon, United Kingdom), adrenaline (Tecan UK Ltd, Reading, United Kingdom) and insulin (Mercodia, Uppsala, Finland) concentrations (intra-plate CVs: $4.0 \%, 6.8 \%, 5.8 \%$ and $4.9 \%$, respectively). Plasma nitrite concentrations were determined by ozone chemiluminescence (Bailey et al., 2009). Briefly, $500 \mathrm{uL}$ of heparinised plasma was deproteinised by addition of $500 \mathrm{uL}$ ice-cold ethanol and centrifuged for $10 \mathrm{~min}$ at $2360 \mathrm{~g}$. Thereafter, the supernatant was introduced to a gas-tight purge vessel via $200 \mathrm{uL}$ injections into the septum at the top of the vessel. The nitrite concentration of plasma was determined by its reduction to NO in the presence of glacial acetic acid and aqueous sodium iodide (4\% wt/vol). The spectral emission of electronically excited nitrogen dioxide, derived from the reaction of NO with ozone, was detected by a thermoelectrically cooled, red-sensitive photomultiplier tube housed in a Sievers gas-phase chemiluminescence nitric oxide analyzer (Sievers NOA 280i; Analytix, Durham, UK). The signal (mV) area was converted to a concentration by using the regression equation derived from plotting the $\mathrm{mV}$ area obtained using nitrite standards spanning the $\mathrm{nM}$ concentration range. Blood glucose concentrations were determined by a Biosen C-line (Barleben, Germany) and 
haemoglobin concentration by a Yumizen H500 (Horiba Medical, Montpellier, France) automated analyser. Haematocrit, determined in duplicate using a microcentrifuge, and haemoglobin were used to correct IL-6, IL1ra, nitrite, adrenaline and insulin concentrations for changes in plasma volume, as well as glucose concentrations for changes in whole blood volume (Dill and Costill, 1974). Whole body insulin sensitivity was calculated using glucose and insulin concentrations during the OGTT, according to the Matsuda index (Matsuda and DeFronzo, 1999).

\section{Statistical analysis}

All data are presented as mean $\pm \mathrm{SD}$. Normality and sphericity were checked by the Shapiro Wilk and Mauchley`s test, respectively. Changes in physiological and thermoregulatory parameters as well as blood glucose and plasma adrenaline concentrations were analysed by 2-way repeated measures ANOVA, using paired samples students $T$-tests for pairwise comparisons when significant interactions were detected. Changes in perceptual measures, IL-6, IL-1ra, nitrite and insulin concentration were analysed non-parametrically. First, the Friedman test was used to test for an effect of time in each condition, where after Wilcoxon signed-rank tests were used for pairwise comparisons. $P$-values are reported without a Bonferroni correction (Nakagawa, 2004). Incremental areas under the curve (iAUC) for IL-6, glucose and insulin were calculated using the trapezoidal method. Cohen`s $d$ effect sizes (ES) and their $95 \%$ confidence interval were calculated for the main outcome measures as the mean difference between conditions divided by the pooled standard deviation (the latter calculated as the squared root of the sum of both conditions`squared SDs divided by two). An ES of $0.2 \theta, 0.5 \theta$ and $0.8 \theta$ is interpreted as a small, moderate and large effect, 
respectively (Cohen, 1992). The $24^{\text {th }}$ version of SPSS (Chicago IL, USA) was used for

295

296

297

298

299

300

301

302

303

304

305

306

307

308

309

310

311

312

313

314

315

\section{Results}

\section{Thermoregulatory responses}

The rise in $\mathrm{T}_{\text {rec }}$ was attenuated in LBH compared with WBH (Time $\mathrm{x}$ Condition $p<0.001)$. Nonetheless, $\mathrm{T}_{\text {rec }}$ at the end of LBH was higher than CON $(p=-0.001)$. Deep tissue temperature was elevated to a larger extent by WBH compared with the other conditions (Time $\mathrm{x}$ Condition $p<0.001$ ), while the $\mathrm{T}_{\mathrm{dt}}$ during $\mathrm{LBH}$ was also higher compared with CON from 30 min onwards $(p<0.001)$ (Fig. 2). There was no difference in the change in body mass between conditions (CON: $0.08 \pm 0.07 \mathrm{~kg}, \mathrm{LBH}: 0.07 \pm 0.21$ kg, WBH: $0.18 \pm 0.32 \mathrm{~kg} ; p=-0.321)$.

\section{Cardiovascular responses}

Blood flow in the common femoral artery was elevated to a larger extent by WBH compared with the other conditions (Time $\mathrm{x}$ Condition $p<0.001$; ES pre vs. post $\Delta \mathrm{WBH}-\Delta \mathrm{LBH}: 3.04(2.4$ to 3.7$)$; ES pre vs. post $\Delta \mathrm{WBH}-\Delta \mathrm{CON}: 5.4(4 . \underline{8}$ to $6 . \underline{1}))$, while it was also higher during LBH compared with CON $(p=0.002$; ES pre vs. post $\Delta$ : 1.84(1.2 to 2.5$))$. There was no difference in femoral artery blood flow between conditions during the OGTT (i.e. post+90 $\min , p=-0.521$ ). Shear rate in the femoral artery was higher in WBH compared with LBH $(p<0.001)$, and in LBH compared with $\mathrm{CON}$ at $45 \mathrm{~min}$ and $90 \mathrm{~min}(p<0.038)$. Blood flow in the brachial artery was only elevated during WBH $(p<0.001)$ (Table 1). 


\section{Inflammatory and glycaemic responses}

The cytokine, nitrite and adrenaline response to the three conditions are shown in Fig. 3. Plasma IL-6 concentrations were elevated from pre in all three conditions $(p<0.004)$. Interleukin-6 concentrations were higher following WBH compared with $\mathrm{CON}$ at post $+120 \mathrm{~min}$ and post $+180 \mathrm{~min}(p<0.022)$. There was no difference in IL-6 concentration between LBH and CON at any time point ( $p>0.121)$. However, the IL-6 iAUC of both LBH and WBH were higher compared with CON $(p<0.047$; ES WBH CON: $0.7(0.0$ to $1 . \underline{3}$; ES LBH $-\mathrm{CON}$ : $0.8(0.2$ to $1 . \underline{5})$, while there was no difference between $\mathrm{LBH}$ and WBH ( $p=-0.285$; ES LBH $-\mathrm{WBH}$ : 0.4 (-0.2 to 1.0). Plasma interleukin-1 ra concentration was only elevated following WBH $(p=-0.007$; ES: 0.4(0.0 to 0.9 ). In addition, plasma nitrite concentration was elevated after WBH only ( $p=$ 0.025; ES: 0.9 $(0.2$ to 1.5$))$. Plasma adrenaline concentration was higher following WBH compared with both other conditions $(p<0.001)$, and following LBH compared with $\operatorname{CON}(p=-0.027)$.

There was a Time $\mathrm{x}$ Condition interaction for blood glucose concentrations during 332 the OGTT $(p=-0.046)$. The glucose iAUC of WBH was larger compared with the other 333 conditions $(p<0.028$; ES WBH $-\mathrm{CON}: 1 . \underline{3}(0.6$ to 1.9 ; ES WBH $-\mathrm{LBH}: 1 . \underline{9}(1.2$ to $2 . \underline{5})$, while there was no difference between $\mathrm{LBH}$ and $\mathrm{CON}(p=-0.266$; ES: $0 . \underline{4}(-0 . \underline{3}$ to $\underline{1.0})$. There were no differences in plasma insulin concentration between conditions during the OGTT for any of the time points $(p>0.090)$. There was also no difference in the

337 insulin iAUC between conditions $(p=-0.273)$ (Fig. 4). There was no difference between 338 the conditions in whole body insulin sensitivity as determined by the Matsuda Index

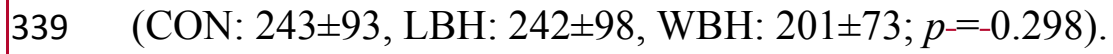


Perceptual responses

The perceptual responses to the three conditions are shown in Table 2. Thermal sensation was only elevated during WBH $(p<0.001)$. In comparison to the other two conditions, TS was higher during WBH from 15 min onwards $(p<0.004)$ and remained higher at the end of the session $(p<0.004)$. There were no differences in TS between LBH and CON $(p>0.084)$. Thermal comfort scores only increased during WBH $(p<0.001)$, indicating a higher perceived discomfort associated with the heat. Thermal comfort was different from the other two conditions from 15 min into WBH onwards $(p<0.009)$ and remained higher until the end of the session $(p<0.005)$. Basic affect only changed during WBH $(p<0.001)$ and was more negative compared with LBH and CON 351 from $30 \min (p<0.010)$ up to the end of the session $(p-=-0.005)$.

\section{Discussion}

This study investigated the acute effects of local versus whole-body passive

354 heating on inflammatory, glycaemic, vascular as well as perceptual measures. While the 355 perceptual responses were more positive, the acute IL-1 ra, nitrite and femoral artery 356 shear rate responses were attenuated after LBH when compared with WBH. However, 357 Tthe IL-6 iAUC following LBH did not differ from WBH and was elevated compared with CON.

Comparing studies that have investigated whole-body passive heating protocols suggest the existence of a dose-response relationship between heat exposure, the associated rise in $\mathrm{T}_{\text {core, }}$ and the acute IL-6 response (Hoekstra et al., 2018; Leicht et al., 2015; Faulkner et al., 2017; Laing et al., 2008). In the present study, however, LBH led 
to a considerable increase in $\mathrm{T}_{\mathrm{dt}}$ and $\mathrm{T}_{\text {skin }}$ in the legs, while the rise in $\mathrm{T}_{\mathrm{rec}}$ was only

LBH provides tentative support for the notion of skeletal muscle as a "heat sensor";

suggesting that as long as skeletal muscle is heated, a large elevation in $\mathrm{T}_{\text {core }}$ is not

required for a systemic IL-6 response to occur. This is supported by ex-vivo studies that show an increase in IL-6 production and secretion following heating of skeletal muscle tissue (Welc et al., 2012). It should be noted, however, that cold stress can also stimulate IL-6 production (Yildrim et al., 2010). Therefore, although $\mathrm{T}_{\mathrm{dt}}$ was not measured in the upper body, the cooling applied to that body region during LBH may have contributed to the circulating IL-6 concentration following that condition. Apart from the direct effects of skeletal muscle heating, the small but significant increase in adrenaline concentration and shear rate during LBH may also have stimulated IL-6 production. Indeed, adrenaline infusion alone elevates plasma IL-6 concentrations in resting humans (Steensberg et al., 2001), likely via the activation of $\beta$-adrenergic 377 pathways (De Rijk et al., 1994), and an increase in shear rate stimulates IL-6 production 378 by endothelial cells in vitro (Sterpetti et al., 1993). Of note, in the current study the IL-6 iAUC was elevated following LBH when compared with CON, but there were no differences between both conditions at individual time points. Nonetheless, the iAUC forms a summary measure of IL-6 concentrations throughout a trial, accounting for the presence of peak concentrations at different post-session time points between trials (Papanicolaou et al., 1996). in counteracting chronic low-grade inflammation is predominantly based upon its 
stimulatory effect on the production of anti-inflammatory cytokines such as IL-1ra and IL-10 (Petersen and Pedersen, 2005), the relevance of the elevated IL-6 iAUC following LBH could be questioned. Other factors not measured in the present study may have triggered the IL-1ra response following WBH, such as the activation of macrophages and monocytes by IL-4, C-reactive protein and lipopolysaccharide (Tilg et al., 1994). Additionally, the IL-1ra concentration can peak later than $1 \mathrm{~h}$ post-exercise (Hoekstra et al., 2017). With the final blood sample at $1 \mathrm{~h}$ post-session, the peak IL-1ra concentration following LBH may have been missed.

Circulating nitric oxide, reflected by plasma nitrite concentrations (Clough and Thrush, 1967), is instrumental for vasodilation (Laughlin et al., 2008) and can stimulate glucose uptake (Roberts et al., 1997). In keeping with the IL-1ra response, nitric oxide bioavailability was elevated after WBH only. There are several potential explanations for the lack of an acute nitrite response following LBH-existed despite an elevation in femoral artery shear rate. It is likely that the increase in femoral artery shear rate during $\underline{\mathrm{LBH}}$, which was indeed smaller compared with WBH, was insufficient to induce systemic increases in nitrite concentration. Furthermore, whilst femoral artery share rate was increased during LBH, brachial artery shear rate was reduced compared with CON as a result of the upper-body cooling, which may have limited nitric oxide production.

An acute increase in shear rate without detectable changes in circulating markers may nonetheless induce local vascular adaptations. For instance, using a within-subject design, blood flow restriction to attenuate shear rate in the arm during handgrip exercise blunts vascular adaptations in the cuffed compared with the non-cuffed arm, despite exposure to the same systemic milieu (Tinken et al., 2010). The increase in femoral artery shear rate during $\mathrm{LBH}$ despite the limited rise in $\mathrm{T}_{\text {core }}$ underscores the potency of 
local heat stimuli to induce changes in blood flow. In keeping with the present study,

412 heating of one leg only does not elevate $\mathrm{T}_{\text {core }}$ but increases femoral artery blood flow to a similar extent as whole-body heating (Chiesa et al., 2015). Moreover, direct heating applied to the skin of the legs increases skeletal muscle blood flow in the absence of a $\mathrm{T}_{\text {core }}$ rise (Heinonen et al., 2011). In this light, it may be somewhat surprising that the increase in femoral artery blood flow and shear rate was lower in LBH compared with 417 WBH. However, although the legs were subjected to the same external heat stimulus, $\mathrm{T}_{\mathrm{dt}}$ and thigh $\mathrm{T}_{\mathrm{sk}}$ were higher in WBH than LBH near the end of the conditions. This may have been the result of cooled blood entering the legs from the upper body in LBH 420 (Raccuglia et al., 2016). Finally, cardiac output was elevated after WBH but not LBH. Previous studies indicate that passive heating can enhance physical capacity (Myamoto et al., 2005), likely through changes in cardiac function (Saltin \& Calbett, 2006). As $\underline{\text { such, the limited cardiac stress induced by LBH suggest that upper-body cooling may }}$ interfere with the beneficial effects of passive heating on physical capacity. in $\mathrm{T}_{\text {core }}$ showed an acute reduction in circulating glucose concentration following heating of the feet (Kobayashi et al., 2019) and hand (Moore et al., 2020). However, in 428 the present study, LBH did not lead to reduced glucose concentrations when compared with CON. The increase in blood flow during LBH might have been too limited to enhance glucose delivery to skeletal muscle (Baron et al., 1994), or the heating applied to the legs may have been of insufficient intensity to stimulate the glucose sensitising

432 processes observed in ex_-vivo tissue heating studies, such as GLUT4 translocation

433 (Goto et al., 2015) and a heat shock protein 72 (Hsp72)-mediated reduction in c-Jun N434 terminal kinase activity (Gupte et al., 2011). When compared with WBH, on the other 
hand, LBH resulted in lower postprandial glucose concentrations, likely related to the attenuated adrenaline response to the local heating protocol (Hargreaves et al., 1998). exacerbated in healthy, lean individuals compared with people having type 2 diabetes mellitus (Knudsen et al., 2014); suggesting that acutely elevated postprandial glucose concentrations after exercise (or passive heating) are not necessarily detrimental for long-term health. Future studies may explore the significance of the acute post-heating glucose response for the adaptations in glucose metabolism following repeated passive heating.

\section{Practical implications and future directions}

While a body of literature on physiological responses to heat therapy has emerged in the past decade, data on perceptual responses to this intervention and

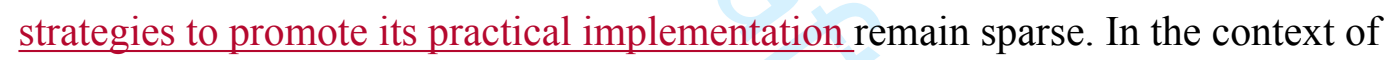
exercise, perceptual responses during the activity are predictive of attitudes towards as well as engagement in future physical activity (Rhodes and Kates, 2015). As such, it has been postulated that the prescription of high exercise intensities may hinder exercise adherence due to the negative relationship between intensity and the affective response (Ekkekakis et al., 2011). In comparison, the FS scores reported at the end of WBH were more negative (Hoekstra et al., 2017; Astorino and Thum, 2018; Jung et al., 2014) or comparable (Oliveira et al., 2013) to high-intensity exercise; while the TS and TC scores also reached near-maximal negative values towards the end of this condition. At the same time, there was no difference in the perceptual responses between LBH and CON. Although limited longitudinal data exists on the relationship between these measures and adherence to passive heating interventions, it suggests that more localised 
459 heating protocols may be considered as a strategy to enhance adherence to passive heat 460 treatment.

It should be acknowledged that the acute increase in the majority of the

462 cardiometabolic markers included in the present study was attenuated by upper-body

463 cooling. Therefore, there likely exists a trade-off between the tolerability of passive

464 heating and its efficacy to improve cardiometabolic health. With the various aspects of

465 passive heating that can be adjusted in mind (e.g. session duration, water or air

466 temperature, part of the body that is heated, cooling interventions), it may be advisable

467 to tailor sessions to the tolerance of each individual. Further reducing the imposed heat

468 stress when compared with the LBH protocol employed in the present study may lead to

469 a complete absence of acute changes in cardiometabolic markers. Although the

470 implications of IL-6 may go beyond the induction of an anti-inflammatory response,

471 evidenced by a larger reduction in adipose tissue mass in people taking IL-6 blockers

472 during a chronic exercise programme compared with placebo (Wedell-Neergaard et al.,

473 2019), we suggest that more considerable heat stress and concomitant rise in

474 physiological parameters (e.g. $\mathrm{T}_{\text {core, }}$ arterial blood flow, cardiac output) are needed to

475 induce an acute increase in a larger array of systemic markers. -Future studies may

476 explore the minimum thermal load needed to acutely increase the circulating

477 concentrations of markers such as nitrite and anti-inflammatory cytokines. Building on

478 the findings of the present study, lower-body heating without or in combination with

479 more modest upper-body cooling may be an avenue to do so. Of note, as perceptual

480 responses to heat stress may alter after repeated exposure (Gibson et al., 2015), careful

481 monitoring of perceptual responses may allow practitioners or end-users to raise the

482 imposed heat strain over the course of an intervention. Above all, chronic intervention 
studies are warranted to establish the efficacy of repeated local heating to improve

cardiometabolic health.

\section{Study limitations}

First, while passive heating interventions are arguably most relevant for people at risk for chronic non-communicable diseases and with restricted ability to be physically active, here recreationally active, healthy males were studied. However, a relatively homogenous sample was considered preferable to establish the efficacy of local heating protocols, informing future studies in populations at risk for metabolic illhealth. Notwithstanding, it should be noted that the inclusion of this (male) population combined with the relatively small sample size limits the implications of the findings. Studies from the exercise literature, for instance, suggest different acute perceptual and cardiometabolic responses to a bout of exercise in people at-risk for cardiometabolic disease (Ekkekakis et al., 2011; Knudsen et al., 2014). Future studies may thus build on the data presented here by investigating larger samples of males and females at a heightened risk for cardiometabolic disease. Furthermore, although the present study was powered to detect an acute change in IL-6 concentration based on a study that investigated a local heating protocol (Hashizaki et al., 2018), statistical power may have

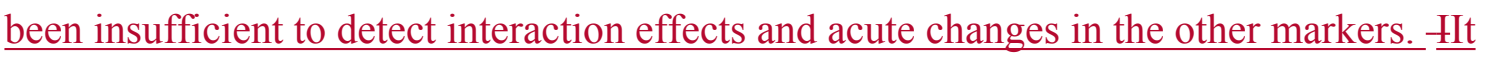
should also be noted that the protocols tested in the current study were of relatively long duration. As such, the perceptual responses during shorter duration whole-body heating may not deviate as much from local heating protocols as in the present study.

Furthermore, the inclusion of other anti-inflammatory cytokines in addition to IL-1ra, $\underline{\text { such as IL-4 and IL-10, would have provided a more comprehensive insight into the }}$ anti-inflammatory response to passive heating. 
$507 \quad$ Finally, while the non-invasive zero-heat flow method can give a reliable

508 estimate of $\mathrm{T}_{\mathrm{dt}}$ at the level of the vastus lateralis (Binzoni et al., 1999) and the increase

509 in $\mathrm{T}_{\mathrm{dt}}$ during WBH was comparable to studies employing similar heating protocols

510 (Kuhlenhoelter et al., 2016; Chiesa et al., 2015), the needle thermometer technique

511 remains the gold standard for $\mathrm{T}_{\mathrm{dt}}$ measurements.

512 Conclusion

513 While LBH led to more favourable perceptual responses compared with $\mathrm{WBH}_{2}=$

514 the acute increase in markers related to improvements in the inflammatory profile (IL-

515 1ra), nitric oxide generation (nitrite) and vascular function (femoral artery shear rate),

516 but not the IL-6 iAUC, was attenuated when compared with WBH. Therefore, the

517 findings of the present study suggest that a trade-off between positive perceptual

518 responses and the acute increase in cardiometabolic markers is likely to exist when

519 administering passive heating protocols.

520 Acknowledgements

521

The authors thank Christian Andersen for his excellent assistance during data

522 collection and Prof. George Havenith and Dr Alex Lloyd, who kindly provided the

523 water-perfused suit. This project was supported by the Kyoten Research Center of

524 Sports for Persons with Impairments.

525

526

Conflict of interest

527

The authors have no conflict of interest to declare. 


\section{References}

Astorino, T.A., Thum, J.S. 2018. Interval training elicits higher enjoyment versus moderate exercise in persons with spinal cord injury. J. Spinal Cord Med. 41(1), 77-84.

Bailey, S. J., Winyard, P., Vanhatalo, A., Blackwell, J. R., DiMenna, F. J., Wilkerson, D. P., Jones, A. M. 2009. Dietary nitrate supplementation reduces the $\mathrm{O} 2$ cost of low-intensity exercise and enhances tolerance to high-intensity exercise in humans. J. Appl. Physiol. 107, 1144-1155.

Baron, A.D., Steinberg, H., Brechtel, G., Johnson, A. 1994. Skeletal muscle blood flow independently modulates insulin-mediated glucose uptake. Am. J. Physiol. Endocrin. Metabol. 266(2), 248-253.

Binzoni, T., Springett, R., Dalton, J. C. P., \& Delpy, D. 1999. A new combined deep-bodytemperature/NIRS probe for non-invasive metabolic measurements on human skeletal muscle. Oxygen Transport to Tissue XXI (623-629). Springer, Boston, MA.

Brunt, V. E., Howard, M. J., Francisco, M. A., Ely, B. R., \& Minson, C. T. 2016. Passive heat therapy improves endothelial function, arterial stiffness and blood pressure in sedentary humans. J. Physiol. 594(18), 5329-5342.

Chiesa, S. T., Trangmar, S. J., Kalsi, K. K., Rakobowchuk, M., Banker, D. S., Lotlikar, M. D., \& González-Alonso, J. 2015. Local temperature-sensitive mechanisms are important mediators of limb tissue hyperemia in the heat-stressed human at rest and during small muscle mass exercise. Am. J. Physiol. Heart Circ. Physiol. 309(11), 369-380

Clough, P.N., Thrush, B.A. 1976. Mechanism of chemiluminescent reaction between nitric oxide and ozone. Transactions of the Faraday Society. 63: 915-925.

Cohen, J. 1992. A power primer. Psychol. Bul. 112(1), 155.

Cullen, T., Clarke, N. D., Hill, M., Menzies, C., Pugh, C. J., Steward, C. J., \& Thake, C. D. 2020. The health benefits of passive heating and exercise: to what extent do the mechanisms overlap. J. Appl. Physiol. In press

De Rijk, R.H., Boelen, A., Tilders, F.J., Berkenbosch, F. 1994. Induction of plasma interleukin-6 by circulating adrenaline in the rat. Psychoneuroendocrinol. 19(2), 155-163.

Dill, D. B., Costill, D. L. 1974. Calculation of percentage changes in volumes of blood, plasma, and red cells in dehydration. J. Appl. Physiol. 37(2), 247-248.

Dinenno, F. A., Jones, P. P., Seals, D. R., Tanaka, H. 1999. Limb blood flow and vascular conductance are reduced with age in healthy humans: relation to elevations in sympathetic nerve activity and declines in oxygen demand. Circulation. 100(2), 164-170. 
Dumke, C.L., Slivka, D.R., Cuddy, J.S., Hailes, W.S., Rose, S.M., Ruby, B.C. 2015. The effect of environmental temperature on glucose and insulin after an oral glucose tolerance test in healthy young men. Wilderness Environ. Med. 26(3), 335-342.

Durnin, J. V., Womersley, J. V. G. A. 1974. Body fat assessed from total body density and its estimation from skinfold thickness: measurements on 481 men and women aged from 16 to 72 years. Br. J. Nutr.. 32(1), 77-97.

572 Ekkekakis, P., Parfitt, G., Petruzzello, S.J. 2011. The pleasure and displeasure people feel when they 573 exercise at different intensities. Sports Med. 41(8), 641-671.

574 Epstein, Y., Moran, D. S. 2006. Thermal comfort and the heat stress indices. Industr. Health. 44(3), 388575398.

576 Faulkner, S.H., Jackson, S., Fatania, G., Leicht, C.A. 2017. The effect of passive heating on heat shock 577 protein 70 and interleukin-6: A possible treatment tool for metabolic diseases? Temperature. 4(3), 292578304.

579 Frank, S. M., Raja, S. N., Bulcao, C. F., \& Goldstein, D. S. 1999. Relative contribution of core and 580 cutaneous temperatures to thermal comfort and autonomic responses in humans. J. Appl. Physiol. 86(5), $581 \quad 1588-1593$.

Gibson, O. R., Mee, J. A., Tuttle, J. A., Taylor, L., Watt, P. W., \& Maxwell, N. S. (2015). Isothermic and fixed intensity heat acclimation methods induce similar heat adaptation following short and long-term timescales. J. Therm. Biol. 49(2015), 55-65.

585

586

587

588

589

590

591

592

593
Goto, A., Egawa, T., Sakon, I., Oshima, R., Ito, K., Serizawa, Y., Hayashi, T. 2015. Heat stress acutely activates insulin-independent glucose transport and 5'-AMP-activated protein kinase prior to an increase in HSP 72 protein in rat skeletal muscle. Physiol. Rep. 3(11), 12601-12612.

Gupte, A.A., Bomhoff, G.L., Touchberry, C.D., Geiger, P.C. 2011. Acute heat treatment improves insulin-stimulated glucose uptake in aged skeletal muscle. J. Appl. Physiol. 110(2), 451-457.

Hardy, C. J., Rejeski, W. J. 1989. Not what, but how one feels: the measurement of affect during exercise. J. Sport Exerc. Psych. 11(3), 304-317.

Hargreaves, M., Angus, D., Howlett, K., Conus, N.M., Febbraio, M. 1996. Effect of heat stress on glucose kinetics during exercise. J. Appl. Physiol. 81(4), 1594-1597.

Hashizaki, T., Nishimura, Y., Teramura, K., Umemoto, Y., Shibasaki, M., Leicht, C. A., Tajima, F. 2018. Differences in serum IL-6 response after $1 \mathrm{C}$ rise in core body temperature in individuals with spinal cord injury and cervical spinal cord injury during local heat stress. Int. J. Hyperther. 35(1), 541-547.

Heinonen, I., Brothers, R.M., Kemppainen, J., Knuuti, J., Kalliokoski, K.K., Crandall, C.G. 2011. Local heating, but not indirect whole-body heating, increases human skeletal muscle blood flow. J. Appl. Physiol. 111(3), 818-824.

Hoekstra, S.P., Bishop, N.C., Faulkner, S.H., Bailey, S.J., Leicht C.A. 2018. Acute and chronic effects of hot water immersion on inflammation and metabolism in sedentary, overweight adults. J. Appl. Physiol. 125(12), 2008-2018.

Hoekstra, S.P., Bishop, N.C., Leicht, C.A. 2017. Can intervals enhance the inflammatory response and enjoyment in upper-body exercise? Eur. J. Appl. Physiol. 117(6), 1155-1163.

Hoekstra, S.P., Bishop, N.C., Leicht, C.A. 2020. Elevating body temperature to reduce low-grade inflammation: a welcome strategy for those unable to exercise? Exerc. Imm. Rev. 26, 42-55. 
607 Jung, M. E., Bourne, J. E., Little, J. P. 2014. Where does HIT fit? An examination of the affective 608 response to high-intensity intervals in comparison to continuous moderate-and continuous vigorous609 intensity exercise in the exercise intensity-affect continuum. PloS One. 9(12), 1-18.

610 Kitabchi AE, Umpierrez GE, Murphy MB, Barrett EJ, Kreisberg RA, Malone JI, Wall BM. 2001. 611 Management of hyperglycemic crises in patients with diabetes. Diabetes Care. 24(1), 131-153.

612 Knudsen, S.H., Karstoft, K., Pedersen, B.K., Van Hall, G., Solomon, T.P. 2014. The immediate effects of 613 a single bout of aerobic exercise on oral glucose tolerance across the glucose tolerance 614 continuum. Physiol. Rep. 2(8), 12114.

615 Kobayashi, R., Hashimoto, Y., Okamoto, T. 2019. Effects of acute footbath before and after glucose 616 ingestion on arterial stiffness. J. Clin. Biochem. Nutr. 64, 164-169.

617 Koshinaka, K., Kawamoto, E., Abe, N., Toshinai, K., Nakazato, M., Kawanaka, K. 2013. Elevation of 618 muscle temperature stimulates muscle glucose uptake in vivo and in vitro. J Physiol Sci. 63(6), 409-418.

619 Kuhlenhoelter, A.M., Kim, K., Neff, D., Nie, Y., Blaize, A.N., Wong, B.J., Roseguini, B.T. 2016. Heat 620 therapy promotes the expression of angiogenic regulators in human skeletal muscle. Am. J. Physiol. Reg. 621 Integr. Comp. Physiol. 311(2), 377-391.

622 Laing, S.J., Jackson, A.R., Walters, R., Lloyd-Jones, E., Whitham, M., Maassen, N., Walsh, N.P. 2008.

623 Human blood neutrophil responses to prolonged exercise with and without a thermal clamp. J. Appl.

624 Physiol. 104(1), 20-26.

625 Laughlin, M.H., Newcomer, S.C., Bender, S.B. 2008. Importance of hemodynamic forces as signals for 626 exercise-induced changes in endothelial cell phenotype. J. Appl. Physiol. 104(3), 588-600.

627 Leicht, C.A., Kouda, K., Umemoto, Y., Banno, M., Kinoshita, T., Moriki, T., Tajima, F. 2015. Hot water 628 immersion induces an acute cytokine response in cervical spinal cord injury. Eur. J. Appl. Physiol. $629 \quad 115(11), 2243-2252$.

630 Leicht, C.A., James, L.J., Briscoe, J.H., Hoekstra, S.P. 2019. Hot water immersion acutely increases 631 postprandial glucose concentrations. Physiol. Rep. 7(20), 14223-14.

632 Lewis, J. F., Kuo, L. C., Nelson, J. G., Limacher, M. C., \& Quinones, M. A. 1984. Pulsed Doppler 633 echocardiographic determination of stroke volume and cardiac output: clinical validation of two new 634 methods using the apical window. Circulation. 70(3), 425-431.

635 Maley, M. J., Hunt, A. P., Stewart, I. B., Faulkner, S. H., \& Minett, G. M. 2019. Passive heating and 636 glycaemic control in non-diabetic and diabetic individuals: A systematic review and meta-analysis. PloS 637 one, 14(3), e0214223.

638 Miyamoto, H., Kai, H., Nakaura, H., Osada, K., Mizuta, Y., Matsumoto, A., \& Imaizumi, T. (2005). 639 Safety and efficacy of repeated sauna bathing in patients with chronic systolic heart failure: a preliminary 640 report. J. Card. Fail., 11(6), 432-436.

641 Matsuda, M., DeFronzo, R. A. 1999. Insulin sensitivity indices obtained from oral glucose tolerance 642 testing: comparison with the euglycemic insulin clamp. Diabetes Care. 22(9), 1462-1470.

643 Moore, J., Kressler, J., \& Buono, M. J. 2020. Hand heating lowers postprandial blood glucose 644 concentrations: A double-blind randomized controlled crossover trial. Complement. Ther. Med. 49, 645102280.

646 Mündel, T., Hooper, P.L., Bunn, S.J., Jones, D.A. 2006. The effects of face cooling on the prolactin 647 response and subjective comfort during moderate passive heating in humans. Exp. Physiol. 91(6), 10076481014. 
Nakagawa, S. 2004. A farewell to Bonferroni: the problems of low statistical power and publication bias. Behav. Ecol. 15(6), 1044-1045.

Oliveira, B. R., Slama, F. A., Deslandes, A. C., Furtado, E. S., antos, T. M. 2013. Continuous and highintensity interval training: which promotes higher pleasure? PloS One. 8(11), 1-6.

Papanicolaou, D.A., Petrides, J.S., Tsigos, C., Bina, S., Kalogeras, K.T., Wilder, R., Chrousos, G.P. 1996. Exercise stimulates interleukin-6 secretion: inhibition by glucocorticoids and correlation with catecholamines. Am. J. Physiol. Endocr. Metab. 271(3), 601-605.

Petersen AMW, Pedersen BK. 2005. The anti-inflammatory effect of exercise. J. Appl. Physiol. 98(4), 1154-1162.

Raccuglia, M., Lloyd, A., Filingeri, D., Faulkner, S. H., Hodder, S., \& Havenith, G. 2016. Post-warm-up muscle temperature maintenance: blood flow contribution and external heating optimisation. Eur. J. Appl. Physiol. 116(2), 395-404. risk prediction: a systematic review with meta-analysis. Int. J. Cardiol. 168(1), 344-351.

Rhodes, R.E., Kates, A. 2015. Can the affective response to exercise predict future motives and physical activity behavior? A systematic review of published evidence. Ann. Behav. Med. 49(5), 715-731.

Roberts, C.K., Barnard, R.J., Scheck, S.H., Balon, T.W. 1997. Exercise-stimulated glucose transport in skeletal muscle is nitric oxide dependent. Am. J. Physiol. Endocr. Metabol. 273(1), 220-225.

667 Saltin, B., \& Calbet, J. A. 2006. Point: in health and in a normoxic environment, VO2 max is limited 668 primarily by cardiac output and locomotor muscle blood flow. J. Appl. Physiol. 100(2), 744-748.

669 Steensberg, A., Toft, A.D., Schjerling, P., Halkjær-Kristensen, J., Pedersen, B.K. 2001. Plasma 670 interleukin-6 during strenuous exercise: role of epinephrine. Am. J. Physiol. Cell Physiol. 281(3), 10016711004. 1ra, IL-10, and cortisol in humans. Am. J. Physiol. Endocrin. Metabol. 285(2), 433-437. 911-914.

Thomas, K. N., van Rij, A. M., Lucas, S. J., Cotter, J. D. 2017. Lower-limb hot-water immersion acutely induces beneficial hemodynamic and cardiovascular responses in peripheral arterial disease and healthy, elderly controls. Am. J. Physiol. Reg. Integr. Comp. Physiol. 312(3), 281-291.

Tilg, H., Trehu, E., Atkins, M.B., Dinarello, C.A., Mier, J.W. 1994. Interleukin-6 (IL-6) as an antiinflammatory cytokine: induction of circulating IL-1 receptor antagonist and soluble tumor necrosis factor receptor p55. Blood. 83(1), 113-118.

683 Tinken, T.M., Thijssen, D.H., Hopkins, N., Dawson, E.A., Cable, N.T., Green, D.J. 2010. Shear stress 684 mediates endothelial adaptations to exercise training in humans. Hypertension. 55(2), 312-318.

685 Wedell-Neergaard, A. S., Lehrskov, L. L., Christensen, R. H., Legaard, G. E., Dorph, E., Larsen, M. K., 686 \& Ball, M. 2019. Exercise-induced changes in visceral adipose tissue mass are regulated by IL-6 687 signaling: a randomized controlled trial. Cell Metabol. 29(4), 844-855.

688 Welc, S.S., Phillips, N.A., Oca-Cossio, J., Wallet, S.M., Chen, D.L., Clanton, T.L. 2012. Hyperthermia 689 increases interleukin-6 in mouse skeletal muscle. Am. J. Physiol. Cell Physiol. 303(4), 455-466.

690 Yildirim, N. C., \& Yurekli, M. 2010. The effect of adrenomedullin and cold stress on interleukin-6 levels 691 in some rat tissues. Clin. Exp. Immunol. 161(1), 171-175. 
Fig. 1 The set-up and procedures of the experimental conditions. Emergency foil was used to prevent heat loss at the heated body parts. Inserts indicate the temperature of the water infused into each part of the suit. CON: control; LBH: lower-body heating; WBH: whole-body heating. $\sqrt{ }$ represents the following measures: heart rate, blood pressure, perceptual responses and temperature measures; represents blood samples; represents consumption of the dextrose solution; \represents cardiovascular ultrasound measures.

Fig. 2 Thermoregulatory responses to the three experimental conditions (mean $\pm \mathrm{SD}$ ). Shown are A) rectal temperature, $\mathrm{B}$ ) deep tissue temperature and $\mathrm{C}-\mathrm{F}$ ) skin temperature. $\mathrm{CON}$ : control; LBH: lower-body heating; WBH: whole-body heating, p: post. * different from CON, \# different from LBH $(p<0.05)$.

Fig. 3 The interleukin-6 (A and B), adrenaline (C), nitrite (D) and interleukin-1 receptor antagonist (E) concentrations in response to the three experimental conditions. Bars represent the group mean, while the lines represent individual data points. CON: control; LBH: lowerbody heating; WBH: whole-body heating. * effect of time, \# different from other two conditions, $\$$ different from CON $(p<0.05)$.

Fig. 4 The glycaemic response to an OGTT following the three experimental conditions. Shown are concentrations during the OGTT and the incremental are under the curve for glucose (A and $\mathrm{B}$, respectively) and insulin ( $\mathrm{C}$ and $\mathrm{D}$, respectively). Bars represent the group mean, while the lines represent individual data points. CON: control; $\mathrm{LBH}$ : lower-body heating; WBH: wholebody heating, p: post. The dextrose solution was consumed at $\mathrm{p}+60{ }^{*}$ effect of time, \# different from other two conditions $(p<0.05)$. 
733

734

735

736

737

738

739

740

741

742

743 


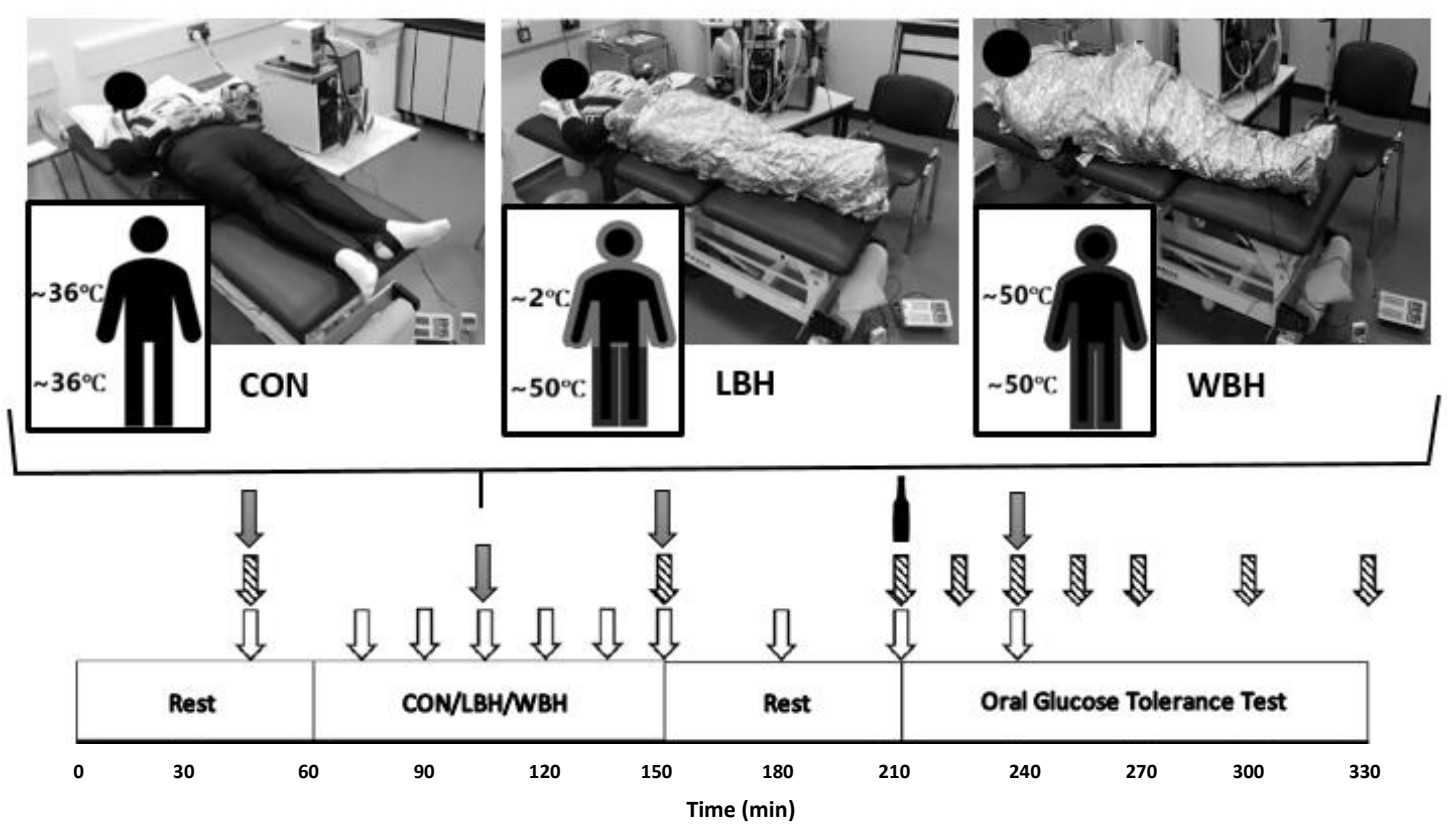




\section{$\bigcirc \operatorname{coN} \bigcirc \mathrm{LBH} \square$ WBH}
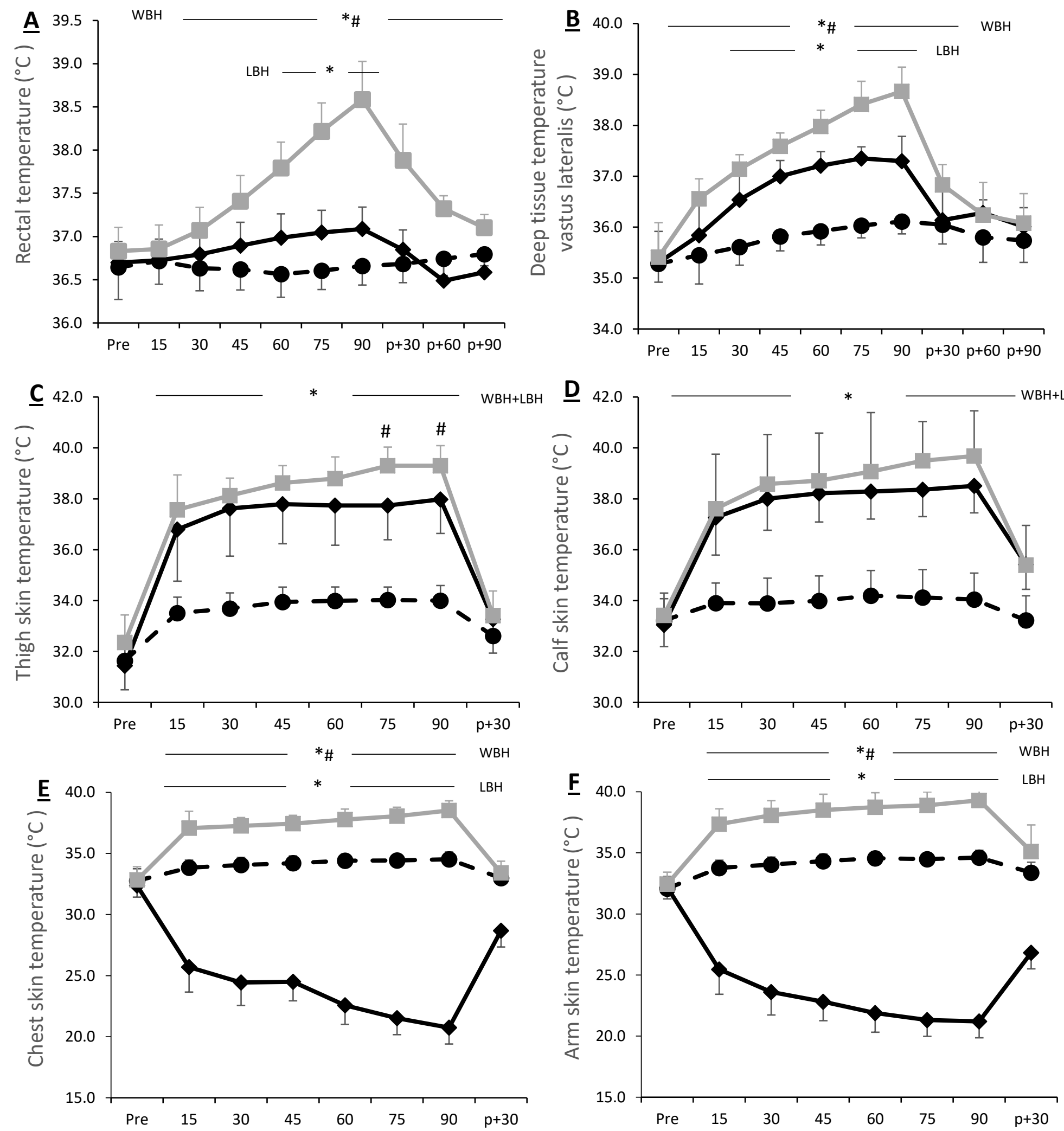


\section{$\square$ соп $\mathbb{1 в н}_{\text {вн }} \square$ мвн}
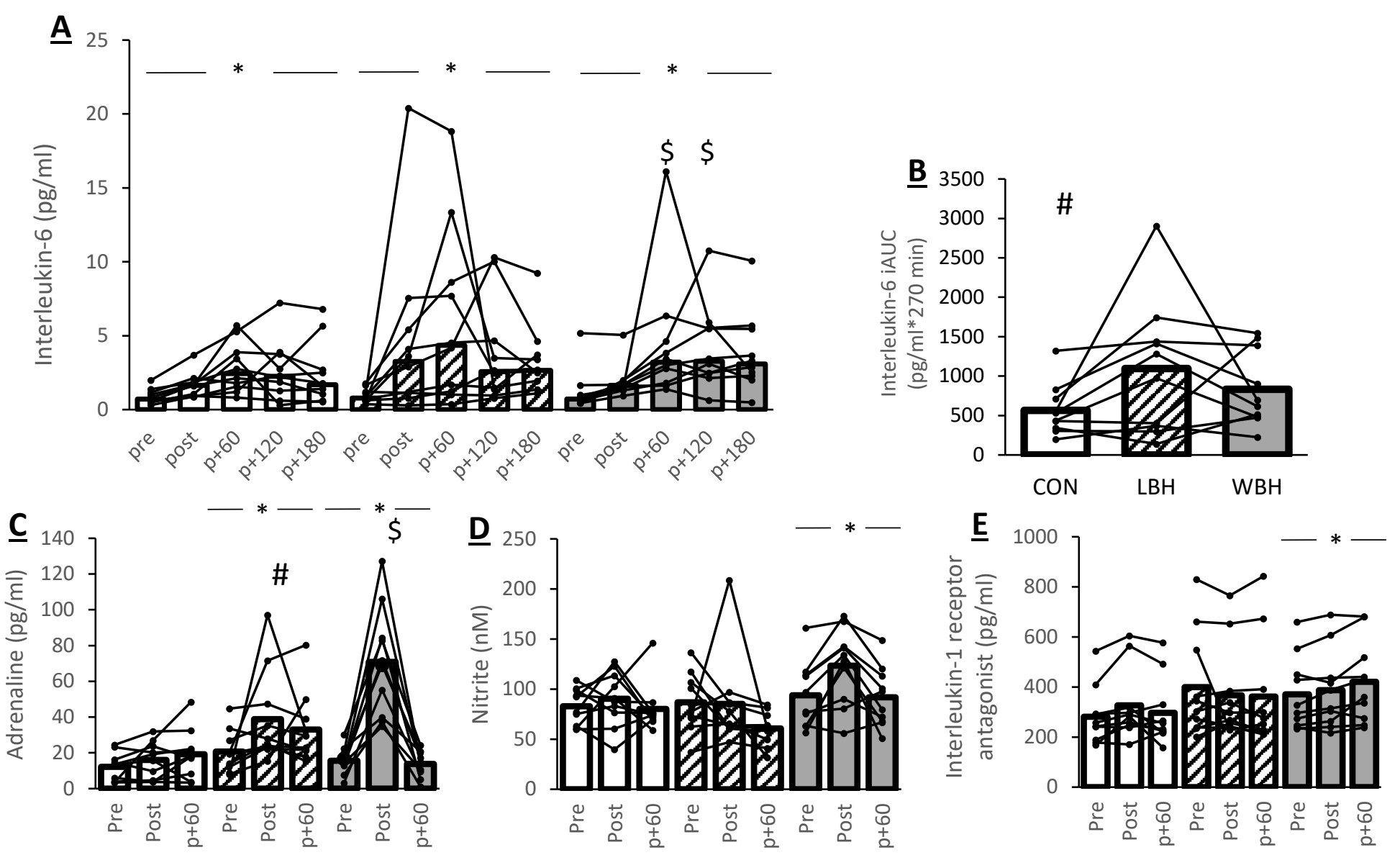

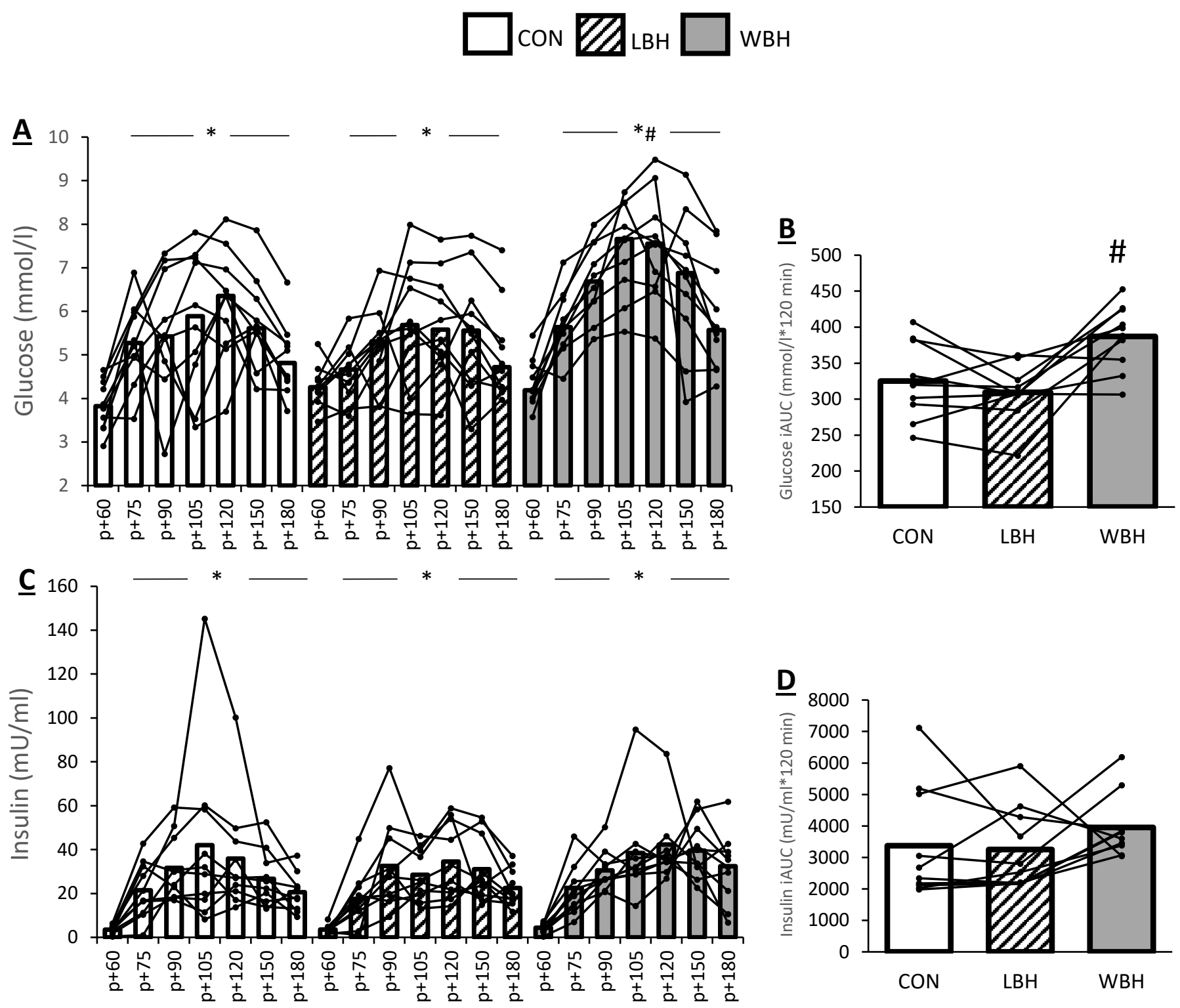
Table 1. Cardiovascular responses to the three experimental conditions (mean $\pm \mathrm{SD}$ ).

\begin{tabular}{|c|c|c|c|c|c|c|}
\hline $\begin{array}{l}\text { Parameter } \\
\text { (ANOVA) }\end{array}$ & Condition & & & Time & & \\
\hline \multirow{4}{*}{$\begin{array}{l}\mathrm{HR} \\
\text { (bpm) } \\
\mathrm{T} p<0.001 \\
\mathrm{C} p<0.001 \\
\mathrm{I} p<0.001\end{array}$} & & Pre & $45 \mathrm{~min}$ & End & $\mathrm{p}+60 \min$ & $\mathrm{p}+90 \mathrm{~min}$ \\
\hline & $\mathrm{CON}$ & $58 \pm 15$ & $59 \pm 13$ & $55 \pm 11$ & $56 \pm 13$ & $57 \pm 16$ \\
\hline & LBH & $54 \pm 11$ & $61 \pm 10$ & $59 \pm 10$ & $55 \pm 10$ & $58 \pm 9$ \\
\hline & WBH & $59 \pm 15$ & $90 \pm 16 \#$ & $110 \pm 15^{\#}$ & $62 \pm 17$ & $57 \pm 19$ \\
\hline \multirow{3}{*}{$\begin{array}{l}\text { SBP } \\
(\mathrm{mmHg}) \\
\mathrm{T} p<0.001 \\
\mathrm{C} p=0.001 \\
\mathrm{I} p<0.001\end{array}$} & $\mathrm{CON}$ & $114 \pm 9$ & $125 \pm 10$ & $126 \pm 7$ & $117 \pm 10$ & $122 \pm 9$ \\
\hline & $\mathrm{LBH}$ & $120 \pm 7$ & $130 \pm 13$ & $133 \pm 11$ & $134 \pm 6$ & $129 \pm 10$ \\
\hline & WBH & $118 \pm 8$ & $134 \pm 12^{\#}$ & $145 \pm 19^{\#}$ & $126 \pm 9$ & $125 \pm 12$ \\
\hline \multirow{3}{*}{$\begin{array}{l}\mathrm{DBP} \\
(\mathrm{mmHg}) \\
\mathrm{T} p=0.004 \\
\mathrm{C} p<0.053 \\
\mathrm{I} p<0.732\end{array}$} & $\mathrm{CON}$ & $63 \pm 5$ & $65 \pm 8$ & $68 \pm 5$ & $67 \pm 5$ & $61 \pm 5$ \\
\hline & $\mathrm{LBH}$ & $67 \pm 4$ & $71 \pm 7$ & $73 \pm 8$ & $70 \pm 5$ & $64 \pm 1$ \\
\hline & WBH & $64 \pm 6$ & $64 \pm 4$ & $70 \pm 7$ & $63 \pm 6$ & $63 \pm 7$ \\
\hline \multirow{3}{*}{$\begin{array}{l}\mathrm{CO} \\
(\mathrm{L} / \mathrm{min}) \\
\mathrm{T} p<0.001 \\
\mathrm{C} p<0.001 \\
\mathrm{I} p<0.001\end{array}$} & $\mathrm{CON}$ & $4.35 \pm 1.03$ & - & $4.19 \pm 0.93$ & - & $4.73 \pm 0.93$ \\
\hline & $\mathrm{LBH}$ & $4.08 \pm 0.84$ & - & $4.37 \pm 1.05$ & - & $4.57 \pm 0.86$ \\
\hline & WBH & $4.53 \pm 0.98$ & - & $7.02 \pm 1.80^{\#}$ & - & $4.92 \pm 1.28$ \\
\hline \multirow{3}{*}{$\begin{array}{l}\text { Brachial BF } \\
(\mathrm{ml} / \mathrm{min}) \\
\mathrm{T} p<0.001 \\
\mathrm{C} p<0.001 \\
\mathrm{I} p<0.001\end{array}$} & $\mathrm{CON}$ & $98 \pm 49$ & - & $107 \pm 44$ & - & $98 \pm 46$ \\
\hline & $\mathrm{LBH}$ & $111 \pm 83$ & & $60 \pm 28 *$ & - & $78 \pm 37$ \\
\hline & WBH & $125 \pm 88$ & & $563 \pm 183^{\#}$ & - & $112 \pm 39 \#$ \\
\hline \multirow{3}{*}{$\begin{array}{l}\text { Brachial SR } \\
(/ / \mathrm{s}) \\
\mathrm{T} p<0.001 \\
\mathrm{C} p<0.001 \\
\mathrm{I} p<0.001\end{array}$} & $\mathrm{CON}$ & $88 \pm 35$ & - & $99 \pm 22$ & - & $85 \pm 18$ \\
\hline & LBH & $96 \pm 40$ & - & $60 \pm 16^{*}$ & - & $75 \pm 28$ \\
\hline & WBH & $107 \pm 42$ & - & $376 \pm 100^{\#}$ & - & $94 \pm 26$ \\
\hline \multirow{3}{*}{$\begin{array}{l}\text { Femoral BF } \\
(\mathrm{ml} / \mathrm{min}) \\
\mathrm{T} p<0.001 \\
\mathrm{C} p<0.001 \\
\mathrm{I} p<0.001\end{array}$} & $\mathrm{CON}$ & $612 \pm 226$ & $649 \pm 243$ & $660 \pm 222$ & - & $661 \pm 205$ \\
\hline & LBH & $609 \pm 226$ & $842 \pm 261 *$ & $943 \pm 349 *$ & - & $620 \pm 272$ \\
\hline & WBH & $584 \pm 263$ & $1427 \pm 332^{\#}$ & $1713 \pm 409^{\#}$ & - & $677 \pm 291$ \\
\hline \multirow{3}{*}{$\begin{array}{l}\text { Femoral SR } \\
(/ / \mathrm{s}) \\
\mathrm{T} p<0.001 \\
\mathrm{C} p<0.001 \\
\mathrm{I} p<0.001\end{array}$} & $\mathrm{CON}$ & $54.4 \pm 18.3$ & $54.0 \pm 15.7$ & $52.5 \pm 16.3$ & - & $55.2 \pm 13.6$ \\
\hline & LBH & $49.2 \pm 14.2$ & $65.1 \pm 21.5^{*}$ & $68.6 \pm 27.4^{*}$ & - & $48.6 \pm 13.2$ \\
\hline & WBH & $51.9 \pm 16.6$ & $124.3 \pm 38.6^{\#}$ & $140.4 \pm 36.9^{\#}$ & - & $57.7 \pm 22.2$ \\
\hline \multirow{3}{*}{$\begin{array}{l}\text { Femoral } \\
\text { VC } \\
\text { (U) } \\
\mathrm{T} p<0.001 \\
C p<0.001 \\
\mathrm{I} p<0.001\end{array}$} & $\mathrm{CON}$ & $6.8 \pm 2.1$ & $7.0 \pm 1.8$ & $6.9 \pm 1.9$ & - & $7.3 \pm 1.0$ \\
\hline & $\mathrm{LBH}$ & $6.5 \pm 1.7$ & $8.5 \pm 2.3^{*}$ & $9.6 \pm 4.0^{*}$ & - & $6.5 \pm 1.7$ \\
\hline & WBH & $6.2 \pm 2.1$ & $15.5 \pm 2.4^{\#}$ & $17.4 \pm 3.6^{\#}$ & - & $7.4 \pm 3.0$ \\
\hline
\end{tabular}

CON: control; LBH: lower-body heating; WBH: whole-body heating; HR: heart rate; SBP: systolic blood pressure; DBP: diastolic blood pressure; $\mathrm{CO}$ : cardiac output; BF: blood flow; VC: vascular conductance; SR: shear rate; T $p$ : main effect of Time; $\mathrm{C} p$ : main effect of Condition; I $p$ : Time $\mathrm{x}$ Condition interaction effect; $\mathrm{p}$ : post; * different from CON, \# different from other two conditions $(p<0.05)$. 
Table 2. Perceptual responses to the three experimental conditions (mean $\pm \mathrm{SD})$.

\begin{tabular}{|c|c|c|c|c|c|c|c|c|c|}
\hline Parameter & Condition & & & & & & & & \\
\hline \multirow{3}{*}{ TS (1 to 9 ) } & & Pre & $15 \mathrm{~min}$ & 30 & 45 & 60 & 75 & 90 & $p+30$ \\
\hline & $\mathrm{CON}$ & $4.9 \pm 0.3$ & $5.3 \pm 0.5$ & $5.3 \pm 0.5$ & $5.4 \pm 0.5$ & $5.2 \pm 0.4$ & $5.4 \pm 0.7$ & $5.3 \pm 0.7$ & $4.9 \pm 0.3$ \\
\hline & LBH & $4.9 \pm 0.6$ & $4.5 \pm 1.2$ & $4.3 \pm 1.1$ & $4.4 \pm 1.2$ & $4.5 \pm 1.3$ & $4.8 \pm 1.3$ & $4.7 \pm 1.3$ & $4.8 \pm 0.6$ \\
\hline \multirow{3}{*}{$\mathrm{TC}(-5$ to +5$)$} & $\mathrm{WBH}^{*}$ & $5.0 \pm 0.5$ & $6.8 \pm 0.4^{\#}$ & $7.8 \pm 0.6^{\#}$ & $8.0 \pm 0.7^{\#}$ & $8.1 \pm 0.7^{\#}$ & $8.7 \pm 0.7^{\#}$ & $8.8 \pm 0.4^{\#}$ & $5.2 \pm 0.8$ \\
\hline & $\mathrm{CON}$ & $0.0 \pm 0$ & $0.0 \pm 0$ & $0.0 \pm 0$ & $0.0 \pm 0$ & $0.0 \pm 0$ & $0.0 \pm 0$ & $0.0 \pm 0$ & $0.0 \pm 0$ \\
\hline & LBH & $0.0 \pm 0.5$ & $-0.3 \pm 1.1$ & $-0.1 \pm 0.7$ & $-0.2 \pm 0.8$ & $-0.1 \pm 0.7$ & $-0.5 \pm 1.0$ & $-0.5 \pm 1.2$ & $-0.1 \pm 0.3$ \\
\hline \multirow{4}{*}{$\mathrm{FS}(-5$ to +5$)$} & $\mathrm{WBH}^{*}$ & $-0.3 \pm 0.3$ & $1.1 \pm 0.7^{\#}$ & $2.0 \pm 1.1^{\#}$ & $2.5 \pm 0.8^{\#}$ & $2.8 \pm 0.6^{\#}$ & $3.2 \pm 0.8^{\#}$ & $3.4 \pm 0.7^{\#}$ & $0.2 \pm 0.4$ \\
\hline & $\mathrm{CON}$ & $1.5 \pm 1.8$ & $1.6 \pm 2.0$ & $1.6 \pm 2.0$ & $1.6 \pm 2.0$ & $1.6 \pm 2.0$ & $1.6 \pm 2.0$ & $1.6 \pm 2.0$ & $1.8 \pm 1.7$ \\
\hline & LBH & $1.6 \pm 1.8$ & $1.3 \pm 1.8$ & $1.3 \pm 1.8$ & $1.1 \pm 1.9$ & $1.1 \pm 1.9$ & $1.1 \pm 2.0$ & $1.0 \pm 1.9$ & $1.4 \pm 1.6$ \\
\hline & $\mathrm{WBH}^{*}$ & $1.1 \pm 1.7$ & $0.7 \pm 1.7$ & $-0.4 \pm 1.6^{\#}$ & $-0.9 \pm 1.9^{\#}$ & $-1.5 \pm 1.6^{\#}$ & $-2.5 \pm 2.1^{\#}$ & $-3.0 \pm 1.8^{\#}$ & $1.5 \pm 2.0$ \\
\hline
\end{tabular}

TS: thermal sensation, where a higher number relates to feeling warmer; TC: thermal comfort, where a higher number relates to larger discomfort associated with the heat;

FS: Feeling Scale, where a more negative number relates to feeling more displeasure; $\mathrm{p}$ : post. * effect of time, \# different from other two conditions $(p<0.05)$ 